\title{
AUTOMATIC WINDING GENERATION USING MATRIX REPRESENTATION - ANFRACTUS TOOL 1.0
}

\author{
Daoud Ouamara $^{a, b, *}$, Frédéric Dubas $^{a}$, Mohamed Nadjib Benallal $^{b}$, \\ Sid Ali Randi ${ }^{c}$, Christophe Espanet ${ }^{d}$
}

${ }^{a}$ Département ENERGIE, FEMTO-ST, CNRS, Univ. Bourgogne Franche-Comté, F90000 Belfort, France

${ }^{b}$ Laboratory of Energy $\mathcal{E}$ Smart System LESI, Khemis Miliana University, Ain Defla, Algeria

${ }^{c}$ Renault S.A., Guyancourt, France

${ }^{d}$ Univ. Bourgogne Franche-Comté, Belfort, France

* corresponding author: daoud.ouamara@gmail.com

\begin{abstract}
This paper describes an original approach dealing with AC/DC winding design in electrical machines. A research software called "ANFRACTUS Tool 1.0", allowing automatic generation of all windings in multi-phases electrical machines, has been developed using the matrix representation. Unlike existent methods, where the aim is to synthesize a winding with higher performances, the proposed method provides the opportunity to choose between all doable windings. The specificity of this approach is based on the fact that it take only the slots, phases and layers number as input parameters. The poles number is not requested to run the generation process. Windings generation by matrix representation may be applied for any number of slots, phases and layers. The software do not deal with the manner that coils are connected but just the emplacement of coils in each slot with its current sense. The waveform and the harmonic spectrum of the total magnetomotive force (MMF) are given as result.
\end{abstract}

KEYWORDS: harmonic spectrum, magnetomotive force, matrix representation, winding generation.

\section{INTRODUCTION}

\subsection{Context of this Paper}

Winding is one of the most important and critical elements of electrical machines. The way that the coils are distributed in the slots directly affects the MMF distribution and, therefore, the electromagnetic performances of electrical machines [1-3]. In order to achieve the desired performances for a given application, several types of windings are developed and studied, viz. [4 10]: full-pitch winding, shortpitch (or chorded) winding, long-pitch winding, concentrated around teeth winding, distributed winding, wave winding, winding with one-two speeds, winding with dead coils, basket windings, skein winding, flat loop non-overlapped winding, flat loop overlapped winding (chain winding), skew winding, diamond winding, involute coil winding [4], toroidal winding [5, 6, drum winding [7, helical (or Faulhaber) winding [8, 9], rhombic winding [10], Gramme-ring winding etc. All such windings can be single or two layers, multi-phases, and (non-)symmetrical. However, windings with multi-layers are possible, some studies are made for showing the influence of increasing the number of layers (three and four layers) on performances of concentrated windings for fractional-slot machines [11-15].

In order to synthesize a winding with high performance, analytical methods have been developed. In 1917, a complete mathematical treatment of the
MMF produced by multi-phases armature windings was made using Fourier series decomposition and the content of spatial harmonics was investigated [16]. In [17-20], the differential leakage was studied for (un)balanced, (ir)regular, and (a)symmetrical windings using Goerges vector diagrams (or polygons) [17, 19] or the "Star of slots" method [20. To calculate the properties of the distribution factor of armature windings, 21] represented the back electromotive force or the MMF of coils by the arrangement of vectors (viz., "Star of slots" method). This method was presented with the purpose of laying out balanced wave windings for any number of slots per pole per phase (i.e., the integral-/fractional-slot machines) [22, 23], well explained by [24]. To obtain a layout of concentrated winding with a highest winding factor, 25] and [26] have presented a method based on the decomposition of the number of slots per pole per phase. It is similar to the method used for fractional-slot synchronous machines [27]. [28] has proposed a new algorithmic method enabling the design and the analysis of windings for fractionalslot AC machines by representing it with a matrix, where the rows correspond to the phase-belts and the columns are assigned to the slots of the machine. Using symmetrical-component theory, a balanced winding can be obtained from a combination of unbalanced winding components [29]. This new method is applicable for all multi-phases windings in fractional-slot machines. To predict the balanced winding influence 
on the mutual stator inductances in multi-phases AC machines (without considering dimensional parameters and from the knowledge of the phase, pole and slot numbers), the matrix modeling method can be used [30]. Other techniques for the improvement of an existing winding are implemented. It is shown in 31 that the stator slot-opening influence the amplitude of harmonics in the MMF distribution. To cancel some undesirable harmonics (e.g., the additional stator MMF sub- and super-harmonic components that lead to higher losses in the rotor as well as saturation effects) in fractional-slot machines with concentrated windings, a concept called stator shifting is investigated by 32 . This technique has been applied to a six-phases permanent-magnet machine with low space harmonics for electric vehicle application [33. The idea is to shift two identical stators having a single layer winding by an angle, thus a two layers winding is formed and in this angle of offset, some spatial harmonics are thus eliminated. Another technique based on using stator coils with unequal size (unequal number of turns in the two layers) allow the improvement of the air-gap field waveform 34 .

The need to develop software dealing windings design has grown interest in recent years, but few software are developed. The aim is to automatically synthesize a winding with high performances. For examples, 35 37. developed an application linked to a finite-element program, which offers the possibility to compare different symmetrical windings. 38 proposed an automatic method to determine the optimal winding whose the principle is based on a generalized harmonic winding analysis combined with a multiobjectives genetic algorithm. An educational software for designing wire winding of electrical machines using MATLAB is created by 39. Educational web-based design tools calculate the winding factor [40, 41]. Software based on the "Star of slots" method (viz., scheme or formulas) are developed by L. Alberti (i.e., "Koil 1.1.0") [42] and by A.O.D. Tommaso [43].

\subsection{OBjective OF this PAPER}

Figure 1] shows the input parameters and results of existing tools in comparison with the new AC/DC winding design tool called "ANFRACTUS Tool 1.0". The research software, based on the matrix representation, consists of obtaining all mechanically doable windings. Unlike existing tools, this approach does not require the poles number for generating all windings, it requires only slots, phases and layers number as input parameters. The polarity will be considered after obtainment windings to eliminate those that do not produce the electromagnetic torque. The aim is to find all feasible windings, and then select the most suitable for a given application. The advantage of this method is that it is applicable regardless of the number of slots, phases and layers and generates all types of windings having juxtaposed/superposed coils

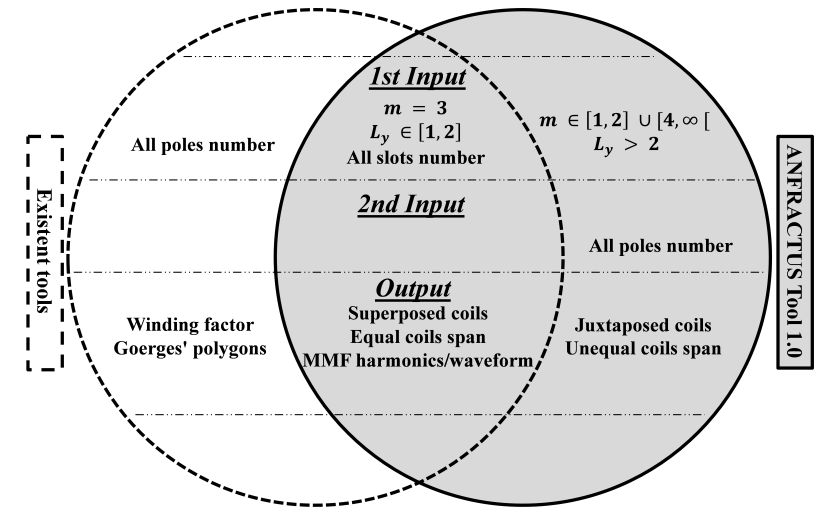

FigURE 1. ANFRACTUS Tool 1.0 capabilities versus existent tools ( $m$ : Number of phases, and $L_{y}$ : Number of layers).

in slots, viz., (un)balanced/(ir)regular/(a)symmetrical windings.

Special technical terms used to describe the method, the matrix representation, and the flowchart explaining this methodology are described in Section 2 A simple example is given to well explain steps of automatic generation of all windings in electrical machines. In Section 3, a new notion of coils disposition is explained, i.e., juxtaposed/superposed coils in slots. Unconventional windings with unequal span are briefly presented. Finally, the graphical user interface as well as an example showing the capability of the tool are presented.

\section{BASIS OF THE METHOD}

\subsection{Technical Terms}

\subsubsection{WINDING AND MATRIX PARAMETERS}

The analogy between winding and associated matrix parameters as shown in Table 1, allow representation of any winding by a matrix, and obtainment of a winding from any matrix. Those parameters allow just the construction of the matrix shape. The filling of the latter, which mean distribution of coils in slots, require the knowledge of the winding layout. It should be noted that the dimension of the winding connection matrix $[C w]$, which represents the windings distribution, is equal to $m \cdot Q_{s} \cdot L_{y}$ composed to $N_{\text {cond }}$ where $Q_{s}, m, L_{y}$, and $N_{\text {cond }}$ are respectively the number of slots, phases, layers, and coil sides per phase.

\section{Applications:}

- $Q_{s}=6, m=3$, and $L_{y}=1:[C w]$ of dimension $3 \times 6$ with $N_{\text {cond }}=2$;

- $Q_{s}=6, m=3$, and $L_{y}=2$ : $[C w]$ of dimension $3 \times 12$ with $N_{\text {cond }}=4$;

- $Q_{s}=20, m=5$, and $L_{y}=2:[C w]$ of dimension $5 \times 40$ with $N_{\text {cond }}=8$;

- $Q_{s}=20, m=5$, and $L_{y}=3:[C w]$ of dimension $5 \times 60$ with $N_{\text {cond }}=12$. 


\begin{tabular}{|c|c|c|c|}
\hline Winding parameters & & & Matrix parameters \\
\hline Number of slots & $Q_{s}$ & $Q_{s} \cdot L_{y}$ & Number of columns \\
\hline Number of phases & \multicolumn{2}{|c|}{$m$} & Number of lines \\
\hline Number of layers & \multicolumn{2}{|c|}{$L_{y}$} & Number of layers \\
\hline Phase belt (electrical ${ }^{\circ}$ ) & $\frac{2 \pi}{m}$ & $\frac{Q_{s} \cdot L_{y}}{m}$ & Vector shift \\
\hline Number of coil sides per phase & $N_{\text {cond }}$ & $\frac{Q_{s} \cdot L_{y}}{m}$ & $\begin{array}{l}\text { Number of forward }(+1) \text { and } \\
\text { return }(-1) \text { conductors per phase }\end{array}$ \\
\hline
\end{tabular}

TABLE 1. Analogy between winding and matrix parameters.
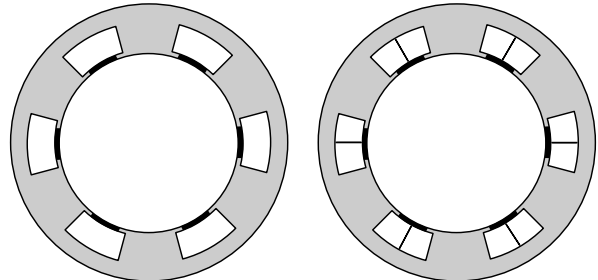

(a)

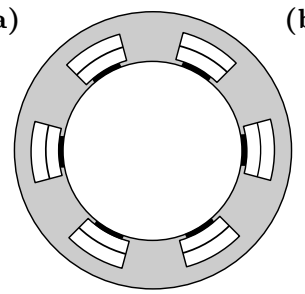

(c)

Figure 2. Coils disposition in slots for (a) single and (b, c) two layers winding: (b) juxtaposed, and (c) superposed.

\subsubsection{COILS DISPOSITION IN SLOTS}

Figure 2 illustrates the coils disposition in slots for single and two layers winding. For single layer winding (see Figure 2a), each slot contain only one coil side. Therefore, the notion of coils dispositions is not visible. In two layers windings, the coils disposition may be juxtaposed (see Figure 2b) or superposed (see Figure 2k). No winding design tools dealing with this difference between the dispositions has been indexed in the literature. Some examples are given in Section 31 to demonstrate this difference.

\subsubsection{TWINS WINDINGS}

To eliminate similar windings at the time of generation process, the notion of twins windings has been introduced. Twins windings are obtained either by rotation of stator (or winding) (see Figure 3b) and/or by inversing it (inverse of current sense) (see Figure 3.). Twins windings are the same with their counterpart windings (see Figure 3a) in terms of physics performances, so the algorithm can detect and eliminate them.

\subsection{Matrix Representation}

The matrix representation allow connection of coils into phase-belts, this notion was introduced by [28]
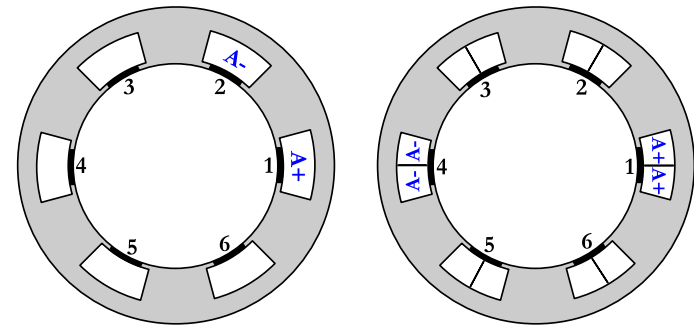

(a)
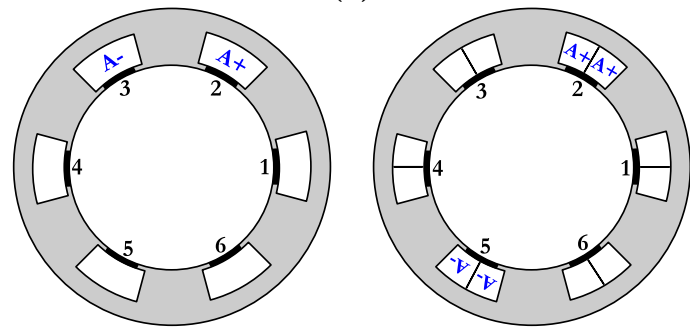

(b)
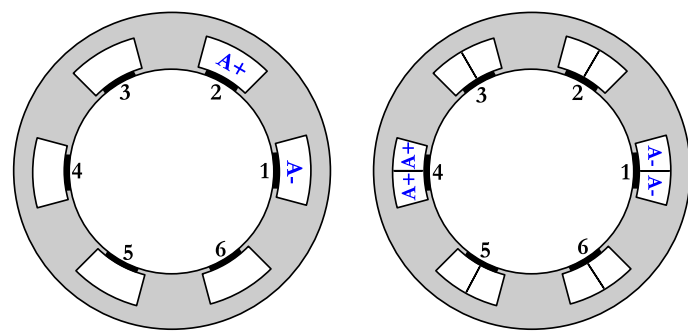

(c)

Figure 3. Twins windings: (a) initial windings, (b) twins by rotation, and (c) twins by inversion.

for designing of fractional-slot windings. In this paper, an amelioration was made to include any number of layers. The matrix rows represent $\mathrm{m}$-phases, while the columns correspond to $Q_{s} \times L_{y}$. The elements ij of the winding connection matrix are defined as follows:

$$
\left[C w_{i j}\right]= \begin{cases}0 & \text { if no conductor, } \\ +1 & \text { if forward conductor } \\ -1 & \text { if return conductor. }\end{cases}
$$

For example, this general representation is applied to some windings as shown in Figure 4, where the feasibility notion is introduced. A feasible single layer 

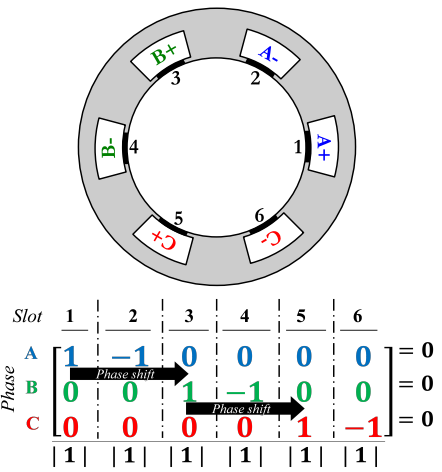

(a)

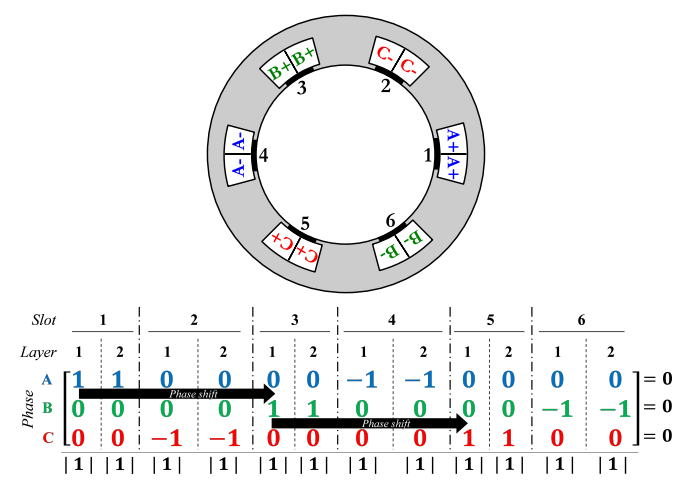

(b)

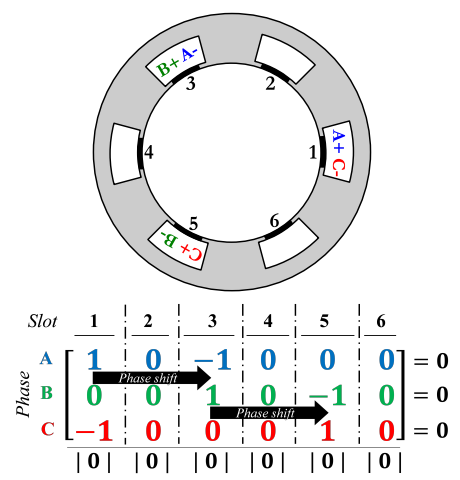

(c)

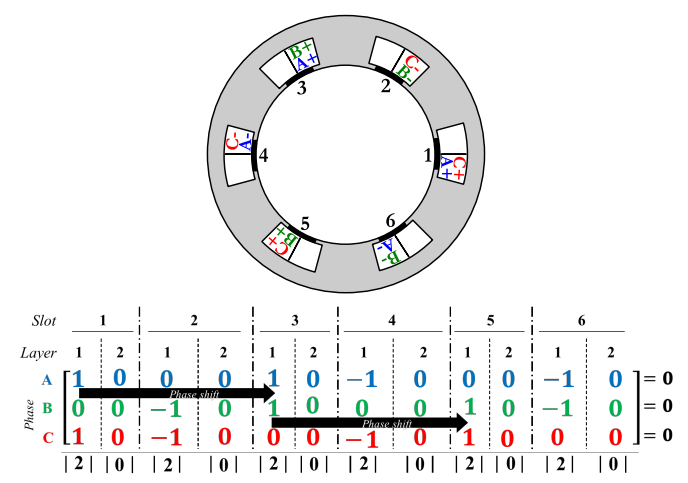

(d)

Note : The arrow symbolizes the phase shift.

Figure 4. Matrix representation of three-phases, e.g.: (a) feasible winding for single layer winding $\left(Q_{s}=6, L_{y}=1\right)$, (b) feasible for two layers winding $\left(Q_{s}=6, L_{y}=2\right)$, (c) non-feasible for single layer winding $\left(Q_{s}=6, L_{y}=1\right)$, and (d) non-feasible for two layers winding $\left(Q_{s}=6, L_{y}=2\right)$. and two layers winding are shown in Figure 4 a and Figure $4 \mathrm{~b}$ respectively. Figure 4 . and Figure $4 \mathrm{~d}$ represent non-feasible windings for single and two layer winding respectively. The two conditions to have a feasible winding are:

$$
\begin{gathered}
\sum \text { line's elements }=0, \\
\sum \text { column's elements }=|1| .
\end{gathered}
$$

The first condition means that the number of coils sides must be even. In other words, for each positive current $(+1)$ a negative one $(-1)$ must exist, to form a coil. The second condition means that each slot may to have $L_{y}$ sides coils. The non-feasible windings shown on Figures 4 c and $4 \mathrm{~d}$ do not meet this requirement. Two sides' coils fill one slot, nevertheless it is a single layer winding. The electrical phase belt, obtained by $2 \pi / m$ for the $m$-phases, is applied in the matrix by circular shifting of the first vector (line). In the matrix reference, the shift is counted by the number of columns obtained by $Q_{s} \times L_{y} / m$.

\subsection{Flowchart of the Methodology}

In this study we used only one vector (one phase) to represent a winding, other phases are been deduced by shifting, with this vector we can get all possible windings by permutation. To minimize the number of possibilities before the process of elimination of the non-feasible windings, only the position of sides coils are taken to generate windings (i.e., no negative sign in the vector). Figure 5 represents the flowchart of the methodology showing gradually the process of the generation associated.

- Stage 1 (Generation step):

$\triangleright$ DATA : The user will be able to enter three parameters $\left\{Q_{s} ; m ; L_{y}\right\}$ (no need to poles number $2 p)$;

$\triangleright$ A first vector will be obtained according to parameters chosen above;

$\triangleright$ All permutation will be made for the first vector and a matrix containing twins, the (non-)feasible windings are obtained;

$\triangleright$ Twins windings will be eliminated, so only unique vector of each winding is kept;

$\triangleright$ According to conditions of feasibility, non-feasible windings will be eliminated;

$\triangleright$ Assignment of sense of current to coils and a final matrix containing unique feasible windings is been obtained.

- Stage 2 (Elimination step according to the number of pole pairs): By selecting a number of pole pairs, the tool will eliminate windings do not producing torque according to the choice of the coils disposition in slots (viz., juxtaposed/superposed coils in slots).

- Stage 3 (Post processing step): This stage concern the post process, viz., the winding drawing (or dia- 
gram), the waveform and the harmonic spectrum of the total MMF at $\omega t=0$.

Application $\left(Q_{s}=6, m=3\right.$, and $\left.L_{y}=1\right)$.

- Stage 1: For this example, the initial vector is $\left[\begin{array}{llllll}1 & 1 & 0 & 0 & 0 & 0\end{array}\right]$. We obtain:

$\triangleright$ All possible permutation of the vector:

$$
\begin{aligned}
& {\left[\begin{array}{cccccc}
1 & 1 & 0 & 0 & 0 & 0 \\
1 & 0 & 1 & 0 & 0 & 0
\end{array}\right] \quad \begin{array}{c}
F \\
N F
\end{array}} \\
& \begin{array}{lllll}
0 & 0 & 1 & 0 & 0
\end{array} \quad F \\
& \begin{array}{lllll}
0 & 0 & 0 & 1 & 0
\end{array} \\
& \begin{array}{lllll}
0 & 0 & 0 & 0 & 1
\end{array} \\
& \begin{array}{lllll|l}
1 & 1 & 0 & 0 & 0 & T
\end{array} \\
& \begin{array}{llllll|l}
0 & 1 & 0 & 1 & 0 & 0 & T
\end{array} \\
& \begin{array}{llllll|l}
0 & 1 & 0 & 0 & 1 & 0 & T \\
0 & 1 & 0 & 0 & 0 & 1
\end{array} \\
& \begin{array}{llllll}
0 & 0 & 1 & 1 & 0 & 0
\end{array} \quad T \\
& \begin{array}{llllll}
0 & 0 & 1 & 0 & 1 & 0
\end{array} \quad T \\
& \begin{array}{llllll}
0 & 0 & 1 & 0 & 0 & 1
\end{array} \\
& \begin{array}{llllll|l}
0 & 0 & 0 & 1 & 1 & 0 & T \\
0 & 0 & 0 & 1 & 0 & 1
\end{array} \\
& {\left[\begin{array}{llllll}
0 & 0 & 0 & 1 & 0 & 1 \\
0 & 0 & 0 & 0 & 1 & 1
\end{array}\right] \quad \begin{array}{l}
1 \\
I
\end{array}} \\
& \text { F : Feasible } \\
& \mathrm{T} \text { : Twins }
\end{aligned}
$$

$\triangleright$ Elimination of twins windings:

$$
\left[\begin{array}{llllll}
1 & 1 & 0 & 0 & 0 & 0 \\
1 & 0 & 1 & 0 & 0 & 0 \\
1 & 0 & 0 & 1 & 0 & 0
\end{array}\right] \quad \begin{gathered}
F \\
N F \\
F
\end{gathered}
$$

$\triangleright$ Elimination of non-feasible windings:

$$
\left[\begin{array}{llllll}
1 & 1 & 0 & 0 & 0 & 0 \\
1 & 0 & 0 & 1 & 0 & 0
\end{array}\right] \quad \begin{aligned}
& F \\
& F
\end{aligned}
$$

$\triangleright$ Assignment of current sense in coils: It is interesting to note that the twins windings by inversion (see Figure 3f) have been eliminated, viz.,

$$
\left[\begin{array}{cccccc}
1 & -1 & 0 & 0 & 0 & 0 \\
1 & 0 & 0 & -1 & 0 & 0
\end{array}\right]
$$

- Stage 2: At the end of the first stage, we obtain two unique feasible windings from data chosen. The first one is a concentrated winding and the second is a full-pitch winding. To be able to eliminate or not eliminate a winding according to the number of pole pairs, a spatial harmonic calculation of those windings is necessary. The amplitudes for each harmonic order are given in Table 2 As known in three-phases electrical machines, the poles number equal to $2 p=3 k$ with $k=0,2,4, \ldots$ do not produce torque because spatial harmonics associated are null ( $h=3 n$ with $n=0,1,2,3, \ldots$ ). This concept is used in the tool to eliminate windings who do not produce torque with the number of pole pairs selected. For this example:

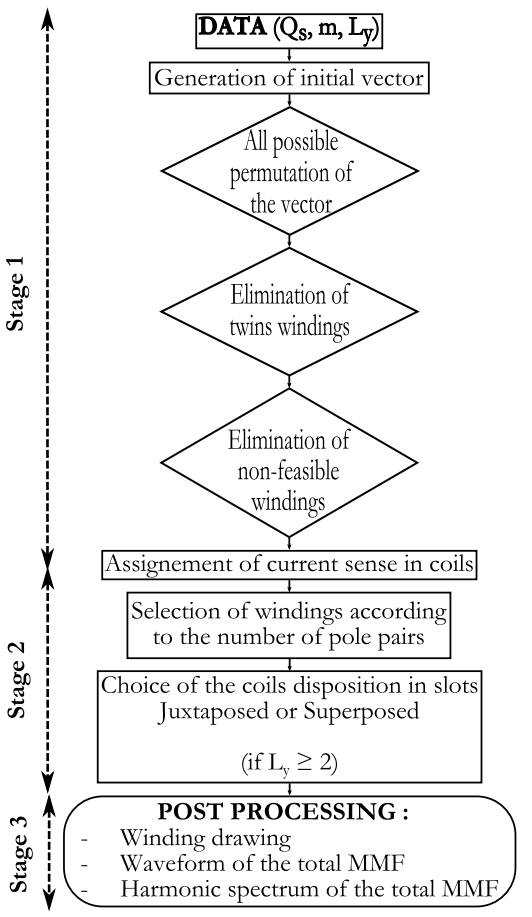

FiguRE 5. Flowchart of the methodology.

$\triangleright 2 p=6,12,18,24,30,36,42,48,54,60$ both of two windings are eliminated;

$\triangleright 2 p=4,8,16,20,28,32,40,44,52,56$ the second winding is eliminated;

$\triangleright 2 p=2,10,14,22,26,34,38,46,50,58$ both of the two windings are selected.

- Stage 3: This stage concern the post process, viz. the winding drawing (or diagram), the waveform and the harmonic spectrum of the total MMF at $\omega t=0$.

It is obvious that this method is applicable for any slots, phases and layers number and allow getting all possible windings. This approach give the poles number compatible with the selected parameters, wich is an interesting data in the electrical machines design (see Table 2). The limited volume of the paper caused the restriction of the presented winding for the simple one. For example, $\left\{Q_{s} ; m ; L_{y}\right\}$ combinations give:

- $\{12 ; 3 ; 1\}$ generate 23 feasible windings, by entering $p=1 \rightarrow 21$ windings that produce torque.

- $\{24 ; 6 ; 1\}$ generate 162 feasible windings, by entering $p=2 \rightarrow 132$ windings that produce torque.

- $\{6 ; 3 ; 2\}$ generate 45 feasible windings, by entering $p=2 \rightarrow 34$ windings that produce torque.

- $\{9 ; 3 ; 2\}$ generate 831 feasible windings, by entering $p=1 \rightarrow 814$ windings that produce torque.

- $\{6 ; 3 ; 3\}$ generate 1,260 feasible windings, by entering $p=2 \rightarrow 1,027$ windings that produce torque.

- $\{8 ; 4 ; 3\}$ generate 5, 139 feasible windings, by entering $p=1 \rightarrow 4,851$ windings that produce torque. 


\begin{tabular}{cccc}
\hline $\begin{array}{c}\text { Poles } \\
\text { number, } \\
2 p\end{array}$ & $\begin{array}{c}\text { Harmonic } \\
\text { order }\end{array}$ & $\begin{array}{c}\text { Amplitude } \\
\text { of first } \\
\text { winding }\end{array}$ & $\begin{array}{c}\text { Amplitude } \\
\text { of second } \\
\text { winding }\end{array}$ \\
\hline 2 & 1 & 0.4777 & 0.9555 \\
4 & 2 & 0.4140 & 0 \\
6 & 3 & 0 & 0 \\
8 & 4 & 0.2063 & 0 \\
10 & 5 & 0.0952 & 0.1904 \\
\hline 12 & 6 & 0 & 0 \\
14 & 7 & 0.0685 & 0.1370 \\
16 & 8 & 0.1039 & 0 \\
18 & 9 & 0 & 0 \\
20 & 10 & 0.0822 & 0 \\
\hline 22 & 11 & 0.0431 & 0.0863 \\
24 & 12 & 0 & 0 \\
26 & 13 & 0.0370 & 0.0740 \\
28 & 14 & 0.0596 & 0 \\
30 & 15 & 0 & 0 \\
\hline
\end{tabular}

$\vdots \quad \vdots \quad \vdots$

TABle 2. Amplitudes for each harmonic order of the two resultant windings.

- $\{10 ; 5 ; 3\}$ generate 15,710 feasible windings, by entering $p=2 \rightarrow 9$, 164 windings that produce torque.

Noting that windings selected will be able to produce torque even if is a low torque.

\section{Results And Discussions}

\subsection{Juxtaposed ANd Superposed Colls IN SLOTS}

To the best of our knowledge, there is no paper referring to the way that coils are disposed in slots, i.e., the juxtaposed/superposed coils in slots. All studies of windings are based on the superposed coils, the coils sides are taken as a same point in the middle of slot. In this section, we demonstrate by examples that the two dispositions are different in terms of the total MMF waveform as well as the harmonic spectrum, so on the electromagnetic performances (rotor eddy-current losses, back electromotive force, torques, ... ).

The study is made for a sinusoidal alimentation and star-connection. However, other current types and connections may be used. The waveform of the MMF along the air-gap is traced with respect to the following assumptions, viz., the slotting effects are neglected and the iron permeability is supposed infinite. For the superposed disposition, the two coils are on the same vertical axis (see Figure 6a). The two coils in a single slot are assimilated to a point in a middle of the slot, therefore crossed at the same instant by associated currents. Hence, a rectangular waveform of MMF is obtained. In the case of juxtaposed disposition, the two coils are on the same horizontal axis and spaced by $\beta$ on the vertical axis (see Figure $6 \mathrm{p}$ ). Unlike the

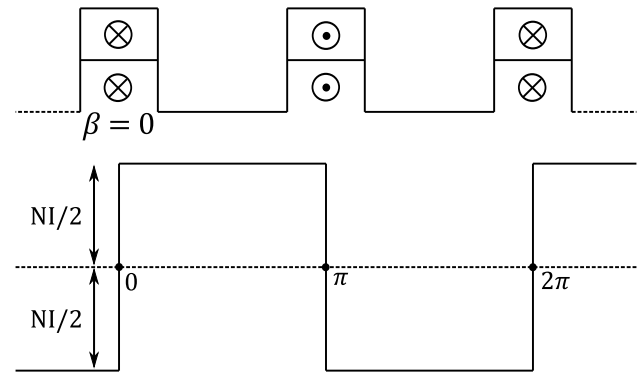

(a)
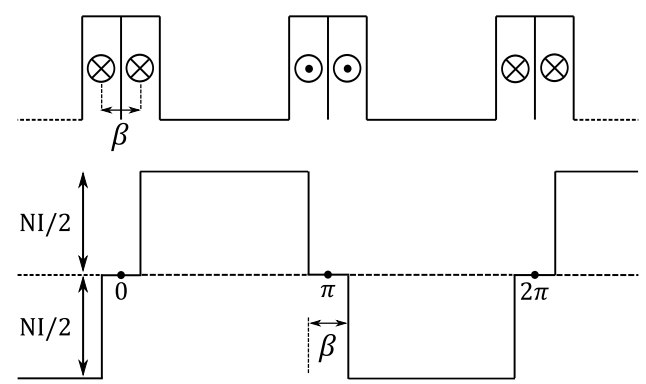

(b)

Figure 6. Waveform of the MMF (for the two coils): (a) superposed, and (b) juxtaposed.

first case, each coil is assimilated to a point centered in the semi-slot. Since, associated currents do not cross at the same instant the two coils of each slot, which resulting in a stairs waveform of MMF. The aim of this study is not to rule on the choice of the best disposition, but to show the difference between the two dispositions, in terms of spatial harmonics content. The total MMF as well as harmonics spectrum are given for the two windings with the two dispositions (viz., superposed and juxtaposed).

For the following two examples, the objective is not to design the best disposition, but to highlight the existent difference between those dispositions.

Example 1. It shows a stator having 6-slots with a two layers full-pitch winding. The superposed and juxtaposed winding are represented in Figure $7 \mathrm{a}$. The waveform and the harmonic spectrum of the total MMF for the two windings are respectively given on Figure $7 \mathrm{p}$ and Figure $7 \mathrm{k}$. The fundamental has the same amplitude for both of the two dispositions, while amplitudes of others harmonics are reduced, or even cancelled for juxtaposed winding in regards to the superposed one.

Example 2. It shows another winding layout for a 6-slots stator. Figure 8 a represents the winding distribution for the two dispositions (viz., superposed and juxtaposed). The waveform and the harmonic spectrum of the total MMF for the two windings are respectively given on Figure $8 \mathrm{~b}$ and Figure $8 \mathrm{c}$. For this example, the fundamental amplitude of the juxtaposed winding decreased and some values of the harmonics of the juxtaposed winding even increased over the values of the superposed winding. 


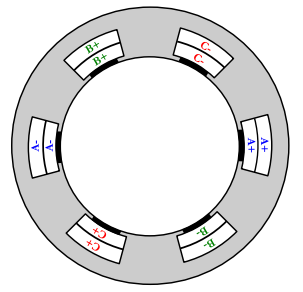

Superposed coils

(a)
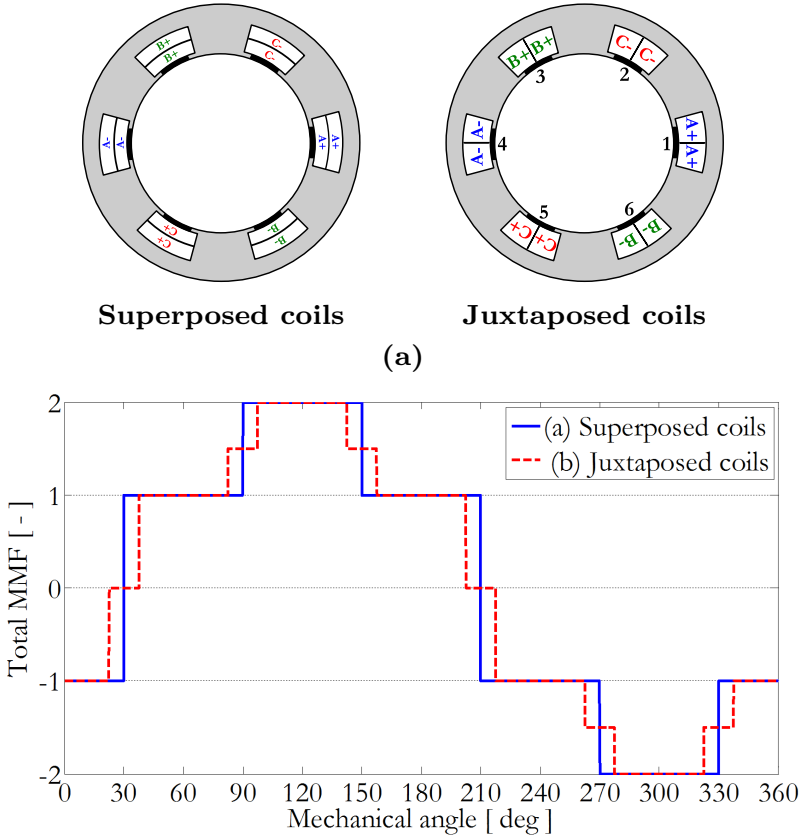

(b)

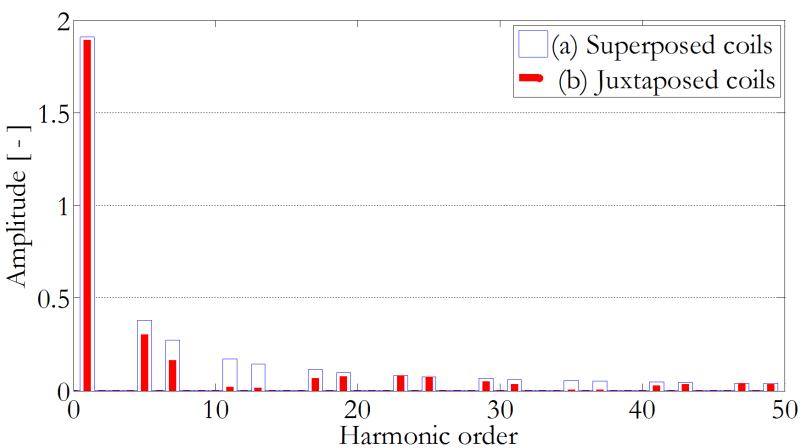

(c)

FiguRE 7 . Comparison of the same winding with different coils disposition (Example 1): (a) superposed and juxtaposed coils, (b) waveform of the total MMF, and (c) harmonic spectrum.

\subsection{Windings with Unequal Spans Coils}

As noted above, the purpose of our work is to cover the entire range of mechanically feasible windings. For this reason, windings having unequal span's coil are not eliminated. Figure 9 shows an example of winding with unequal span's coil. In the literature, no special study is done for this unconventional winding.

\subsection{Graphical User Interface (GUI)}

The GUI of the research software, allow introducing data of an electrical machine's winding (i.e., $Q_{s}, m$, and $L_{y}$ ). The first output is the number of possible windings. The next step consist on defining the number of pair poles $p$ and the second output is the reminding windings able to produce torque with the chosen $p$. Finally, the winding drawing (or diagram), the waveform of the total MMF and its harmonic spectrum are given. The remainder of this paper will be devoted to one example of "ANFRACTUS Tool 1.0".

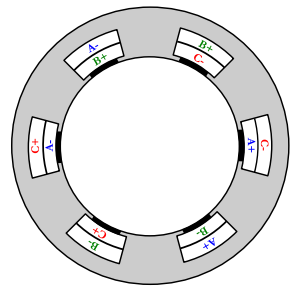

Superposed coils

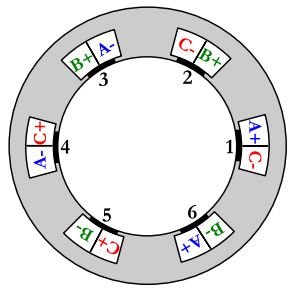

Juxtaposed coils

(a)

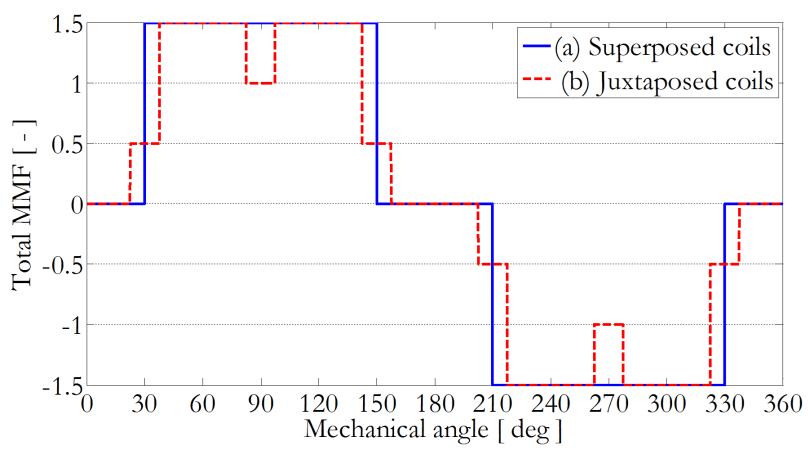

(b)

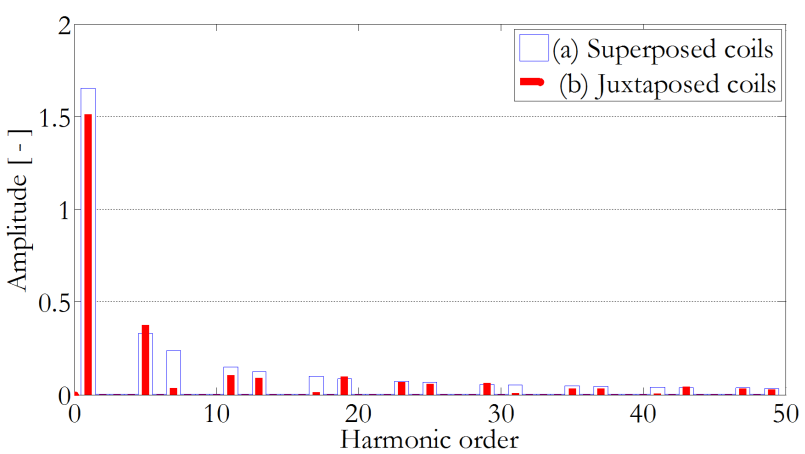

(c)

Figure 8. Comparison of the same winding with different coils disposition (Example 2): (a) superposed and juxtaposed coils, (b) waveform of the total MMF, and (c) harmonic spectrum.

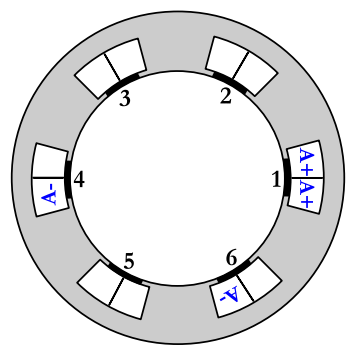

Figure 9. Winding with unequal span's coil.

\subsection{EXAMPLE OF "ANFRACTUS ToOL 1.0"}

In this example, the input parameters are: $Q_{s}=8$, $m=4$, and $L_{y}=3$. The total number of windings generated are $\mathbf{5 , 1 3 9}$ feasible windings for the superposed coils. With $p=1$, the windings number producing torque is equal to $\mathbf{4 , 8 5 1}$. Figure 10 illustrates results of the winding studied. 


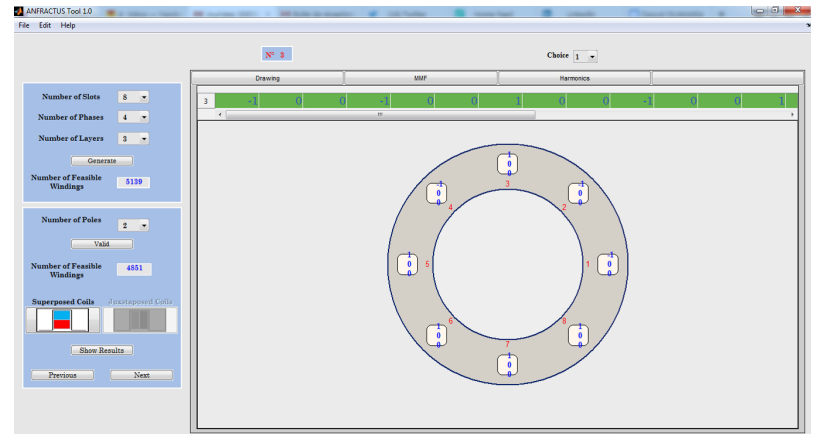

(a)

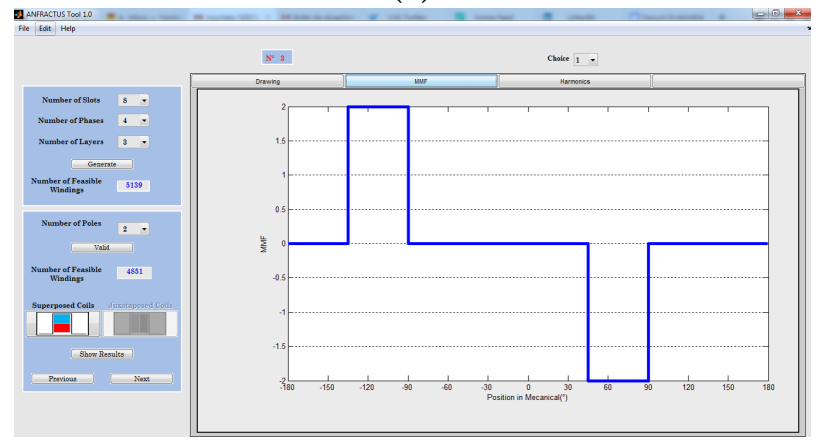

(b)

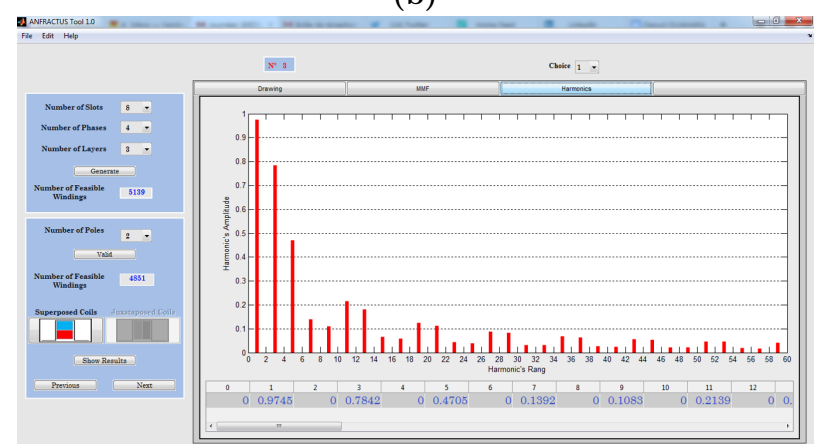

(c)

Figure 10. Example for $Q_{s}=8, m=4$, and $L_{y}=3$ : (a) winding drawing, (b) waveform of the total MMF, and (c) harmonic spectrum.

\section{Conclusion}

An automated procedure for winding generation based on the matrix representation has been presented. The research software is called "ANFRACTUS Tool 1.0". The latter allow two inputs, the first one is about the winding generation process and only a few parameters are required, such as the slots, phases and layers number. The second input consist of poles number and do not interact in the generation process. The method used is well explained in details, flowchart with an example are given to best comprehension of the approach. It is clear that is applicable with all input parameters (viz., slots, phases and layers number).

The tool allows the adequate choice of winding by comparing spatial harmonic content for each winding obtained after the generation process, also the waveform of the total MMF. The vector representing the first phase is displayed with the winding drawing (or diagram). The user will be able to review all possible windings and have a global idea for the choice to make. The concept of juxtaposed and superposed coils is introduced, thereby a comparison of the same winding with the two disposition is possible.

The tool is under a continuous amelioration and in ulterior versions, the software will be linked with an (semi-)analytical model to perform the optimal design of electrical machines, estimate the copper mass used, calculate self-/mutual-inductances. The tool take as output parameters, the feasible windings represented by matrix. Hence, a connection with a semi-analytical model, based on subdomain technique 44 or magnetic equivalent circuit [45, 46], is possible. Since this latter have matrix representing the winding, as an input parameter. The winding factor estimation will be associated by another tool (under finalisation stage). This latter will be linked with this one exposed in this paper.

A perspective may be applied as an alternative of this one presented, it consists to determine the associated winding from the waveform of the magnetic flux density. We have not yet developed this method; it will be studied after more reflection.

\section{REFERENCES}

[1] J. Cros, P. Viarouge, a. Halila. Brush DC motors with concentrated windings and soft magnetic $\backslash$ ncomposites armatures. In Conference Record of the 2001 IEEE Industry Applications Conference. 36th IAS Annual Meeting (Cat. No.01CH37248), vol. 4, pp. 2549-2556. IEEE, 2001. DOI:10.1109/IAS.2001.955979.

[2] F. Magnussen, C. Sadarangani. Winding factors and Joule losses of permanent magnet machines with concentrated windings. IEEE International Electric Machines and Drives Conference, 2003 IEMDC'03 1:333-339, 2003. DOI:10.1109/IEMDC.2003.1211284

[3] J. Hickiewicz, M. Lukaniszyn, S. Szymaniec, P. Wach. On reducing the vibration and noise level of induction motors with integral and fractional slot windings. Archiv fur Elektrotechnik 73(3):163-171, 1990. DOI:10.1007/BF01574023.

[4] P. Dhogal. Basic electrical engineering with numerical problems. Tata McGraw-Hill Publishing Company Limited, 1987.

[5] M. M. Steeves, J. L. Kirtley. Toroidal winding geometry for high voltage superconducting alternators. IEEE Transactions on Power Apparatus and Systems PAS93(6):1902-1908, 1974. DOI:10.1109/TPAS.1974.293842.

[6] F. Bellina, M. Guarnieri, A. Stella. The rfx toroidal field winding design. IEEE Transactions on Magnetics 24(2):1252-1255, 1988. DOI:10.1109/20.11463

[7] F. L. Stone. Drum Shapes as Affecting the Mine Hoist Duty Cycle and Motor Rating. Transactions of the American Institute of Electrical Engineers XXXVII(2):1677-1708, 1918. DOI:10.1109/T-AIEE.1918.4765587.

[8] A. F. Anderson, J. Bumby, B. I. Hassall. Analysis of helical armature windings with particular reference to superconducting a.c. generators. Science, Transmission 
and Distribution, IEEE Proceedings C 127(3):129-144, 1980. DOI:10.1049/ip-c:19800024

[9] F. Fritz. Armature winding for rotary electrical machines, U.S. Patent 3360 668, 1967.

[10] J. M. Richard Rohrer, Jens Schulze, Remy Hofer, Albin Von Moos-Woehrl, Martin Gaul, Peter Mitterbaeck. Electric motor with multilayered rhombic single coils made of wire, U.S. Patent 2007/0 103 025, 2007.

[11] M. Perry. Multiple Layer Series Connected Winding Design for Minimum Losses. IEEE Transactions on Power Apparatus and Systems PAS-98(1):116-123, 1979. DOI:10.1109/TPAS.1979.319520

[12] A. M. El-Refaie, T. M. Jahns. Impact of winding layer number and magnet type on synchronous surface PM machines designed for wide constant-power speed range operation. IEEE Transactions on Energy Conversion 23(1):53-60, 2008. DOI:10.1109/TEC.2007.905053.

[13] M. V. Cistelecan, F. J. Ferreira, M. Popescu. Three phase tooth-concentrated multiple-layer fractional windings with low space harmonic content. In 2010 IEEE Energy Conversion Congress and Exposition, ECCE 2010 - Proceedings, pp. 1399-1405. IEEE, 2010. DOI:10.1109/ECCE.2010.5618267

[14] H. J. Kim, D. J. Kim, J. P. Hong. Characteristic analysis for concentrated multiple-layer winding machine with optimum turn ratio. IEEE Transactions on Magnetics 50(2):14-17, 2014. DOI:10.1109/TMAG.2013.2279100

[15] P. B. Reddy, A. M. EL-Refaie, K.-K. Huh. Effect of Number of Layers on Performance of Fractional-Slot Concentrated-Windings Interior Permanent Magnet Machines. IEEE Transactions on Power Electronics 30(4):2205-2218, 2015. DOI:10.1109/TPEL.2014.2328579

[16] B. Hague. The mathematical treatment of the magnetomotive force of armature windings. Journal of the Institution of Electrical Engineers 55(268):489-514, 1917. DOI:10.1049/jiee-1.1917.0032

[17] R. E. Hellmund, C. G. Veinott. Irregular Windings in Wound Rotor Induction Motors. Transactions of the American Institute of Electrical Engineers 53(2):342346, 1934. DOI:10.1109/T-AIEE.1934.5056632

[18] M. M. Liwschitz. Differential Leakage With Respect to the Fundamental Wave and to the Harmonics. Transactions of the American Institute of Electrical Engineers 63(12):1139-1150, 1944. DOI:10.1109/T-AIEE.1944.5058857

[19] A. O. Di Tommaso, F. Genduso, R. Miceli, G. Ricco Galluzzo. An Exact Method for the Determination of Differential Leakage Factors in Electrical Machines With Non-Symmetrical Windings. IEEE Transactions on Magnetics 52(9):1-9, 2016. DOI:10.1109/TMAG.2016.2562602

[20] H. Xueliang, D. Qiang, H. Minqiang. A Novel Exact and Universal Approach for Calculating the Differential Leakage Related to Harmonic Waves in AC Electric Motors. IEEE Transactions on Energy Conversion 19(1):1-6, 2004. DOI:10.1109/TEC.2003.821828
[21] B. Hague, S. Neville. The properties of the distribution factor of armature windings. Journal of the Institution of Electrical Engineers 60(312):861-866, 1922. DOI:10.1049/jiee-1.1922.0063

[22] M. M. Liwschitz. Balanced Fractional-Slot Wave windings. Transactions of the American Institute of Electrical Engineers 67(1):676-678, 1948. DOI:10.1109/T-AIEE.1948.5059730.

[23] M. M. Liwschitz. Distribution Factors and Pitch Factors of the Harmonics of a Fractional-Slot Winding. Transactions of the American Institute of Electrical Engineers 62(10):664-666, 1943. DOI:10.1109/T-AIEE.1943.5058623.

[24] N. Bianchi, M. Dai Pre. Use of the star of slots in designing fractional-slot single-layer synchronous motors. IEE Proceedings - Electric Power Applications 153(3):459, 2006. arXiv:1011.1669v3 DOI:10.1049/ip-epa:20050284

[25] J. Cros, P. Viarouge. Synthesis of high performance $\mathrm{PM}$ motors with concentrated windings. IEEE International Electric Machines and Drives Conference IEMDC'99 Proceedings (Cat No99EX272) 17(2):725-727, 1999. DOI:10.1109/IEMDC.1999.769226

[26] F. Libert, J. Soulard. Investigation on pole-slot combinations for permanent-magnet machines with concentrated windings. In International Conference on Electrical Machines, January 2004, pp. 5-8. 2004.

[27] A. Ivanov-Smolenski. Electrical Machines, Vol. I. Moscow: Mir Russia, 1982.

[28] P. Wach. Algorithmic method of design and analysis of fractional-slot windings of AC machines. Electrical Engineering 81(3):163-170, 1998. DOI:10.1007/BF01236235.

[29] W. Fong. Polyphase symmetrisation. A new method for the design of electrical-machine windings. Proceedings of the Institution of Electrical Engineers 115(8):1123, 1968. DOI:10.1049/piee.1968.0200

[30] F. Scuiller, E. Semail, J.-F. Charpentier. General modeling of the windings for multi-phase ac machines. The European Physical Journal Applied Physics 50(3):31102, 2010. DOI:10.1051/epjap/2010058

[31] D. Gerling. Influence of the stator slot opening on the characteristics of windings with concentrated coils. In 2009 IEEE International Electric Machines and Drives Conference, pp. 1710-1714. IEEE, 2009. DOI:10.1109/IEMDC.2009.5075433

[32] P. B. Reddy, K.-K. Huh, A. M. EL-Refaie. Generalized Approach of Stator Shifting in Interior Permanent-Magnet Machines Equipped With Fractional-Slot Concentrated Windings. IEEE Transactions on Industrial Electronics 61(9):5035-5046, 2014. DOI:10.1109/TIE.2013.2297515.

[33] A. S. Abdel-Khalik, S. Ahmed, A. M. Massoud. A Six-Phase 24-Slot/10-Pole Permanent-Magnet Machine With Low Space Harmonics for Electric Vehicle Applications. IEEE Transactions on Magnetics 52(6):1-10, 2016. DOI:10.1109/TMAG.2016.2535230 
[34] A. Tessarolo, M. Mezzarobba, A. Contin. A stator winding design with unequally-sized coils for adjusting air-gap space harmonic content of induction machines. In The XIX International Conference on Electrical Machines - ICEM 2010, pp. 1-7. IEEE, 2010. DOI:10.1109/ICELMACH.2010.5608286

[35] C. C. Hwang, S. P. Cheng, P. L. Li. An Automatic Winding Layout Technique for Permanent Magnet Machines. In 2007 IEEE International Electric Machines \& Drives Conference, pp. 766-769. IEEE, 2007. DOI:10.1109/IEMDC.2007.382764

[36] J. Steinbrink. Design and analysis of windings of electrical machines. In 2008 International Symposium on Power Electronics, Electrical Drives, Automation and Motion, pp. 717-720. IEEE, 2008. DOI:10.1109/SPEEDHAM.2008.4581183

[37] C.-c. Hwang, C.-t. Liu, H.-C. Chang. An interactive design of the winding layout in permanent magnet machines. Revue Roumaine des Sciences Techniques Serie Électrotechnique et Énergétique 56:387-395, 2011.

[38] D. Delgado, A. Smith. Automated AC winding design. In 5th IET International Conference on Power Electronics, Machines and Drives (PEMD 2010), pp. 351-351. Institution of Engineering and Technology, 2010. DOI:10.1049/cp.2010.0132

[39] G. Shafipour. The creation of a new educational software for designing wire winding of electrical machines using MATLAB. In in Proc. PEMD, pp. 214-217. York, UK, 2008
[40] Homebuilt Electric Motors. Winding Scheme Calculator. http://www.bavaria-direct.co.za/ scheme/calculator/ [2018-02-01].

[41] F. Meier, S. Meier, J. Soulard. Emetor - An educational web-based design tool for permanent-magnet synchronous machines. In 2008 18th International Conference on Electrical Machines, pp. 16. IEEE, 2008. DOI:10.1109/ICELMACH.2008.4800232.

[42] http://koil.sourceforge.net/.

[43] A. O. Di Tommaso, F. Genduso, R. Miceli. A New Software Tool for Design, Optimization, and Complete Analysis of Rotating Electrical Machines Windings. IEEE Transactions on Magnetics 51(4):1-10, 2015. DOI:10.1109/TMAG.2014.2369860.

[44] Z. Djelloul-Khedda, K. Boughrara, F. Dubas, R. Ibtiouen. Nonlinear Analytical Prediction of Magnetic Field and Electromagnetic Performances in Switched Reluctance Machines. IEEE Transactions on Magnetics 53(7):1-11, 2017. DOI:10.1109/TMAG.2017.2679686

[45] F. Dubas, R. Benlamine, S.-A. Randi, et al. 2-D or quasi 3-D nonlinear adaptative magnetic equivalent circuit, Part I: Generalized modeling with air-gap sliding-line technic. Applied Energy, under review .

[46] R. Benlamine, F. Dubas, S.-A. Randi, et al. 2-D or quasi 3-D nonlinear adaptive magnetic equivalent circuit, Part II: Application to axial-flux interior permanent-magnet synchronous machines. Applied Energy, under review . 